\title{
Decoupling of Economic Growth to Industrial Wastewater Discharge in the Yangtze River Delta
}

\author{
Zhang Kunjie ${ }^{1}$ \\ ${ }^{1}$ School of Finance, Tianjin University of Finance and Economics, Tianjin, China
}

\begin{abstract}
Based on inter-provincial panel data from 2010 to 2018, the author conducted quantitative analysis on the decoupling of economic growth and industrial wastewater discharge as well as its driving factors in the Yangtze River Delta. The research shows during the study period, a high level of decoupling between economic growth and industrial wastewater discharge could be seen in the Yangtze River Delta, mainly in the form of strong decoupling, while at the same time, undesirable conditions such as growth linkages and expansive negative decoupling, still existed in a few years and certain regions. Among the studied regions, Anhui Province, Zhejiang Province and Jiangsu Province all share a similar decoupling pattern with a rather stable overall performance. Shanghai, however, performed poorly among the Yangtze River Delta, with undesirable decoupling states detected in a few years. In terms of driving factors, technology is the core factor that drives the decoupling of economic development to industrial wastewater discharge of the region. The structural effect, on the other hand, is another element worth paying attention to as the technology in the region gradually becomes saturated.
\end{abstract}

\section{Introduction}

The Yangtze River Delta city cluster includes one city (Shanghai) and three provinces (Jiangsu, Zhejiang and Anhui Provinces), generating about $25 \%$ of the nation's economic output with only $2.2 \%$ land. Hence the area holds an important position in China's economic system. Although the river network in the Yangtze River Delta has the highest density in China, the water-people conflict in the region gets even more acute in recent years. In 2020, the water resource per capita in China was 2077.7 cubic meters. The water resource owned by the people in the Yangtze River Delta (area besides Zhejiang Province) is lower than the national per capita. A large amount of wastewater generated during the industrial development of the Yangtze River Delta results in different levels of pollutions in rivers and lakes, and at the same time, poses restrictions on the sustainable development of the region. Therefore, it is of great practical significance to study the decoupling of economic growth to industrial wastewater discharge in the Yangtze River Delta.

First introduced in environmental economics at the end of the $20^{\text {th }}$ century, the decoupling theory refers to the phenomenon that as industrialization keeps advancing, when the economy grows, the total resource consumption falls instead of rising. With the deepening of China's industrialization and the imbalance between water supply and demand, more scholars have turned their eyes to the relationship between economic growth and industrial wastewater discharge. Ma et al. (2017) adopted the Tapio decoupling model to analyze the decoupling between the discharge of industrial wastewater and economic growth in a variety of Chinese provinces and the reasons behind such phenomenon. By analyzing the data of China's economic growth and industrial wastewater discharge collected during 1991 and 2013, He (2016) discovered that decoupling exists between these two elements despite the repeated occurrences of the weak and strong decoupling. $\mathrm{Lu}$ et al. (2020) discovered the uneven development of decoupling in the Yangtze River Delta, with high levels of decoupling in the east and low levels in the west. Nevertheless, the decoupling state in the region still exhibited an upward trend, as weak decoupling was gradually shifting to the strong one.

Though existing researches have delved substantially into the relationship between industrial wastewater discharge and economic development, there are still some areas left to be explored. First, the existing literature mainly analyzes the decoupling of economic growth to wastewater discharge in different regions based on Tapio theory, but the reason accounted for such decoupling was nowhere to be found. Second, the Yangtze River Delta city cluster is the most economically developed and urbanized area with the highest degree of urban agglomeration in China. Each province has a unique resource portfolio and development strategy. However, most literature did not have a detailed analysis of the internal differences within the Yangtze River Delta city cluster. Based on these two points, this paper adopts the Tapio decoupling index and further decomposes it to analyze the temporal and spatial evolutions and the driving factors of the decoupling between economic growth and industrial wastewater discharge in the Yangtze River Delta. 


\section{Research Method}

\subsection{Decoupling index of economic growth to industrial wastewater discharge}

Based on Tapio's research, the decoupling index of economic growth to industrial wastewater discharge can be construed as follows:

$$
\mathrm{e}(\mathrm{IW}, \mathrm{GDP})=\frac{\Delta \mathrm{IW} / \mathrm{IW}}{\Delta \mathrm{GDP} / \mathrm{GDP}}
$$

Wherein, IW represents the total amount of industrial wastewater discharge, GDP is short for gross domestic product, and e (IW, GDP) represents the relative relation between economic growth and the total amount of industrial wastewater discharge.

\subsection{Decoupling index decomposition model}

To further analyze the factors that drive the decoupling, we shall first decompose the decoupling index:

$$
\begin{gathered}
\mathrm{e}(\mathrm{IW}, \mathrm{GDP})=\frac{\Delta \mathrm{IW} / \mathrm{IW}}{\Delta \mathrm{GDP} / \mathrm{GDP}}=\frac{\Delta \mathrm{IW} / \mathrm{IW}}{\Delta \mathrm{IP} / \mathrm{IP}} \times \frac{\Delta \mathrm{IP} / \mathrm{IP}}{\Delta \mathrm{GDP} / \mathrm{GDP}}=\mathrm{e}(\mathrm{IW}, \\
\mathrm{IP}) \times \mathrm{e}(\mathrm{IP}, \mathrm{GDP})
\end{gathered}
$$

Wherein, e (IW, IP) refers to the technical decoupling index, namely the decoupling of industrial added value to the total industrial wastewater discharge in this paper, and e (IP, GDP) represents the structural decoupling index, namely the decoupling of economic growth to industrial added value.

\section{Results and Analysis}

\subsection{Data sources and descriptive statistics}

The data showed Shanghai's total industrial wastewater discharge witnessed a short-term decline in 2010 and rose to 477 million tons in 2012, followed by fluctuating drops in the coming years. In terms of Anhui's industrial wastewater discharge, after several fluctuations from 710 million tons in 2011 to 714 million tons in 2015, it experienced a sharp decline to 496 million tons in 2016 with a decline rate of $30.5 \%$. In the following years, the number dropped to 426 million tons in 2018, with an average rate of $-7.12 \%$. The total amount of industrial wastewater discharge in Zhejiang and Jiangsu Provinces also saw fluctuations, with the number for Zhejiang Province declining from 2.174 billion tons to 1.199 billion tons in 2018, and that for Jiangsu Province falling from 2.638 billion tons in 2010 to 1.436 billion tons in 2018 . As for the industrial added value, all provinces in the Yangtze River Delta demonstrated an upward momentum, with the annual growth rates of Anhui and Jiangsu Provinces above $10 \%$, and relatively low average annual growth rates of $4.61 \%$ and $8.49 \%$ in Shanghai and Zhejiang, respectively. In terms of GDP, all provinces demonstrated an upward momentum with GDP annual growth rates of over $10 \%$, exceeding their average annual growth rates of industrial added value. Among them, the growth rate of Jiangsu's industry is closest to the overall growth rate of the region, with a small discrepancy of $0.71 \%$ between the two numbers, indicating that Jiangsu's economic growth depends heavily on its industrial sector.

\subsection{The temporal and spatial evolutions of decoupling of the economic growth to the total amount of industrial wastewater in the Yangtze River Delta}

Based on the Yangtze River Delta's relevant data from 2010 to 2018 , we can calculate the decoupling index of economic growth to industrial wastewater discharge and obtain the corresponding decoupling states as per the changes of industrial wastewater discharge and the GDP

\begin{tabular}{|c|c|c|c|c|c|c|c|c|}
\hline \multirow[b]{2}{*}{ Time } & \multicolumn{4}{|c|}{ Shanghai } & \multicolumn{4}{|c|}{ Anhui Province } \\
\hline & e (IW, IP) & $\begin{array}{c}\text { Technical } \\
\text { decoupling }\end{array}$ & e (IP, GDP) & $\begin{array}{c}\text { Structural } \\
\text { decoupling }\end{array}$ & e (IW, IP) & $\begin{array}{c}\text { Technical } \\
\text { decoupling }\end{array}$ & e (IP, GDP) & $\begin{array}{c}\text { Structural } \\
\text { decoupling }\end{array}$ \\
\hline 2010 & -0.524 & Strong & 1.480 & $\begin{array}{c}\text { Expansive } \\
\text { negative }\end{array}$ & -0.099 & Strong & 1.447 & $\begin{array}{l}\text { Expansive } \\
\text { negative }\end{array}$ \\
\hline 2011 & 2.093 & $\begin{array}{l}\text { Expansive } \\
\text { negative }\end{array}$ & 0.870 & Growth linkage & -0.014 & Strong & 1.286 & $\begin{array}{c}\text { Expansive } \\
\text { negative }\end{array}$ \\
\hline 2012 & -4.521 & Strong negative & -0.299 & Strong & -0.363 & Strong & 1.093 & Growth linkage \\
\hline 2013 & -2.463 & Strong & 0.241 & Weak & 0.503 & Weak & 0.959 & Growth linkage \\
\hline 2014 & -1.895 & Strong & 0.217 & Weak & -0.334 & Strong & 0.702 & Weak \\
\hline 2015 & -2.509 & Strong negative & -0.413 & Strong & -1.283 & Strong negative & -0.363 & Strong \\
\hline 2016 & -4.002 & Strong & 0.451 & Weak & -3.483 & Strong & 0.803 & Growth linkage \\
\hline 2017 & -1.232 & Strong & 1.273 & $\begin{array}{l}\text { Expansive } \\
\text { negative }\end{array}$ & -1.597 & Strong & 0.779 & Weak \\
\hline 2018 & -2.198 & Strong & 0.205 & Weak & 0.367 & Weak negative & -0.098 & Strong \\
\hline
\end{tabular}
of each province, as shown in Table 1.

Table1. The decoupling of economic growth to industrial wastewater discharge in the Yangtze River Delta

\begin{tabular}{ccccccccc}
\hline \multirow{2}{*}{ Time } & \multicolumn{4}{c}{ Zhejiang Province } & \multicolumn{4}{c}{ Jiangsu Province } \\
\cline { 2 - 8 } & e (IW, IP) & $\begin{array}{c}\text { Technical } \\
\text { decoupling }\end{array}$ & e (IP, GDP) & $\begin{array}{c}\text { Structural } \\
\text { decoupling }\end{array}$ & e (IW, IP) & $\begin{array}{c}\text { Technical } \\
\text { decoupling }\end{array}$ & e (IP, GDP) & $\begin{array}{c}\text { Structural } \\
\text { decoupling }\end{array}$ \\
\hline 2010 & 0.338 & Weak & 0.988 & Growth linkage & 0.174 & Weak & 0.845 & Growth linkage \\
2011 & -1.012 & Strong & 0.965 & Growth linkage & -0.426 & Strong & 0.840 & Growth linkage \\
2012 & -0.837 & Strong & 0.614 & Weak & -0.567 & Strong & 0.725 & Weak
\end{tabular}




\begin{tabular}{|c|c|c|c|c|c|c|c|c|}
\hline 2013 & -0.993 & Strong & 0.753 & Weak & -0.276 & Strong & 2.261 & $\begin{array}{l}\text { Expansive } \\
\text { negative }\end{array}$ \\
\hline 2014 & -3.544 & Strong & 0.385 & Weak & -1.350 & Strong & 0.591 & Weak \\
\hline 2015 & -0.504 & Strong & 0.393 & Weak & 0.191 & Weak & 0.496 & Weak \\
\hline 2016 & -1.422 & Strong & 0.820 & Growth linkage & -1.490 & Strong & 0.847 & Growth linkage \\
\hline 2017 & -1.227 & Strong & 0.459 & Weak & -1.312 & Strong & 1.066 & Growth linkage \\
\hline 2018 & -0.221 & Strong & 0.915 & Growth linkage & -0.885 & Strong & 0.722 & Weak \\
\hline
\end{tabular}

During the study period, strong decoupling was shown between economic growth and industrial wastewater discharge in the Yangtze River Delta, indicating that the region maintained a good momentum of economic growth despite a decline in the total amount of industrial wastewater during the same period. However, differences exist in the decoupling of various provinces. Zhejiang Province performed the best, reporting strong decoupling in most years except the few years at the beginning of the study period. Shanghai, on the other hand, had a quite complicated decoupling record. The municipality started from a bad shape of expansive negative decoupling during 2011 and 2012, before transformed into strong decoupling in 2013 and 2014, which could be attributed to the issue of "Opinions on Implementing the Strictest Water Resources Management System" by China's State Council earlier in 2012. The document called for the establishment of red lines to restrict pollution in water function zones and the improvement of wastewater treatment technology. Anhui Province exhibited strong decoupling in most years other than the two-time weak decoupling seen in 2013 and 2015. Jiangsu Province showed a similar pattern with Anhui, with strong decoupling in most years and weak decoupling in 2010 and 2015.

\subsection{Driving factor analysis on the decoupling of economic growth to industrial wastewater discharge in the Yangtze River Delta}

To further analyze the decoupling between economic growth and industrial wastewater discharge in the Yangtze River Delta and its driving factors, the author tried to break the formerly obtained decoupling index down into technical decoupling index and structural decoupling index.

Table2. Driving factors for the decoupling between economic growth and industrial wastewater discharge in the Yangtze River Delta

\begin{tabular}{ccccc}
\hline \multirow{2}{*}{ Time } & \multicolumn{2}{c}{ Shanghai } & \multicolumn{2}{c}{ Anhui Province } \\
\cline { 2 - 5 } & $\begin{array}{c}\text { e (IW, GDP) decoupling } \\
\text { state }\end{array}$ & Driving factor & $\begin{array}{c}\text { e (IW, GDP) decoupling } \\
\text { state }\end{array}$ & Driving factor \\
\hline 2010 & Strong & Technology & Strong & Technology \\
2011 & Expansive negative & Technology & Strong & Technology \\
2012 & Expansive negative & Structure & Strong & Technology \\
2013 & Strong & Technology & Weak & Technology \\
2014 & Strong & Technology & Strong & Technology \\
2015 & Growth linkage & Structure & Weak & Structure \\
2016 & Strong & Technology & Strong & Technology \\
2017 & Strong & Technology & Strong & Technology \\
2018 & Strong & Technology & Strong & Structure \\
\hline & & & & Jiangsu Province \\
\hline Time & e & & e (IW, GDP) decoupling & Driving factor \\
\hline 2010 & GDP) decoupling & Driving factor & state & Technology \\
2011 & State & Weak & Technology \\
2012 & Weak & Technology & Strong & Technology \\
2013 & Strong & Technology & Strong & Technology \\
2014 & Strong & Technology & Strong & Technology \\
2015 & Strong & Technology & Strong & Technology \\
2016 & Strong & Technology & Weak & Technology \\
2017 & Strong & Technology & Strong & Technology \\
2018 & Strong & Technology & Strong & Technology \\
\hline
\end{tabular}

Technology is the major driving factor in decoupling economic growth to industrial wastewater discharge in the Yangtze River Delta. Since the issue of "Opinions on Implementing the Strictest Water Resources Management System" in 2013, industrial enterprises in the Yangtze River Delta have gradually upgraded their production processes to improve water efficiency and sewage purification technology. Therefore, in most years, industrial wastewater discharge was put under control as the economy kept growing. However, it is worth noting that during the study period, the technical decoupling index of a few years exhibited weak decoupling between the two elements, and a slight increase was shown in the discharge of industrial wastewater. The phenomenon indicated that the region was still in the process of fully implementing the concept of emission reduction. During the formulation and implementation of emission reduction policies, provinces in the region tended to focus on short- 
term goals at the expense of systematicity, which was not good for the long-term and comprehensive achievement of emission reduction goals. We can conclude that as the downward pressure on the economy increased, people were still inclined to sacrifice the environment in exchange for economic stability. In terms of how each province performed, Zhejiang Province recorded the longest period of strong decoupling with excellent sustainability, followed by Jiangsu and Anhui. Shanghai, on the other hand, exhibited the worst performance, reporting two times of expansive negative decoupling and one growth linkage during the study period. As for the reasons, Zhejiang Province actively responded to the call of "Five Water Governance", vigorously promoting industrial transformation and accelerating the upgrading of six major sources of industrial pollution, namely, lead battery production, electroplating, leather making, papermaking, printing and dyeing and chemical engineering by improving wastewater discharge technology. Jiangsu Province is equipped with a solid manufacturing base, a complete range of products and a myriad of industrial enterprises. Under the guidance of the provincial capital Hefei, Anhui Province has a rapidly developing manufacturing industry, in which the launch of relevant policies and measures, as well as the improvement and innovation of production processes, were proven effective in reducing the pressure the industry posed on resources and environment. Unlike other provinces in the Yangtze River Delta, Shanghai is now in the stage of technological saturation, where the amount of industrial wastewater discharge has hit the bottleneck and there is little room for technological upgrading. The result is that the emission reduction performance of Shanghai is less significant than those of other provinces.

As for structural decoupling, during the study period, the Yangtze River Delta exhibited a quite complicated structural decoupling situation. Strong decoupling was never seen in Zhejiang and Jiangsu Provinces, while Shanghai and Anhui Province recorded only two years of strong decoupling. Overall speaking, the states of "growth linkage", "weak decoupling", and "expansive negative decoupling" kept showing in the table, with most years registering a structural decoupling index of less than 1 . This means the secondary industry in the Yangtze River Delta has made a decreasing contribution to the regional economic growth. Shanghai stands at the frontline of China's economy, finance and technological innovation, where the tertiary industry takes up a large proportion of the economy, far exceeding that of the secondary industry. Relying on China's Internet giants, Zhejiang Province has seen vigorous development in its tertiary industry, the integration and upgrading of technology, finance and tourism, all of which ultimately leads to urban innovation. Jiangsu Provinces has advantages in information technology, smart grids, and high-end equipment manufacturing. Moreover, with abundant university resources, the province has a strong scientific research capability, which will be of great help in its industrial transformation. In recent years, the service industry in Anhui Province has grown faster than its secondary industry, which in turn recorded a decreasing contribution to the provincial GDP.

\section{Conclusions}

Based on inter-provincial panel data collected from 2010 to 2018 , the author of this paper analyzed the decoupling of economic growth to industrial wastewater discharge in the Yangtze River Delta from different perspectives. Based on such analysis, the author then quantitatively decomposed the driving factors of decoupling between these two elements. The following conclusions can be drawn:

(1) In general, during the study period, a high level of decoupling between economic growth and industrial wastewater discharge could be seen in the Yangtze River Delta, mainly in the form of strong decoupling, while at the same time, undesirable conditions such as growth linkages and expansive negative decoupling, still existed in a few years and certain regions.

(2) Only small inter-provincial gaps can be seen in the decoupling of economic development to industrial wastewater discharge in the Yangtze River Delta. Anhui Province, Zhejiang Province and Jiangsu Province all share a similar decoupling pattern with a relatively stable overall performance. Shanghai, however, performed poorly in terms of its decoupling state among the Yangtze River Delta, with undesirable decoupling states detected in a few years.

(3) Technology is the core factor that drives the decoupling of economic development and industrial wastewater discharge in the region. The structural effect, on the other hand, is another element worth paying attention to as the technology in the region gradually becomes saturated. Hence the Yangtze River Delta shall speed up economic structure adjustment and deepen the transformation and upgrading of economic development modes.

\section{References}

1. Jiang et al. Research on the Decoupling of Economic Growth and Industrial Water Consumption and its Driving Factors [J]. Journal of Arid Land Resources and Environment, 2019, 33(11): 70-76.

2. Wu D., Wang Y H. Assessment and Prospects on the Decoupling of China's Economic Development and Water Environment Pressure [J]. Resources and Environment in The Yangtze Basin. 2013, 22(09): 1103-1109.

3. Ma et al. Research on the Inter-provincial Differences in the Decoupling of Industrial Wastewater Discharge and Economic Growth [J]. China Population Resources and Environment. 2017, 27(11): 185-192.

4. $\mathrm{Lu}$ et al. Innovation-driven Research on the Decoupling of Economic Growth and Industrial Wastewater Discharge - With the City Clusters in Yangtze River Delta as the Example [J]. Areal Research and Development. 2020, 39(05): 156-162.

5. Yu et al. Decomposition of Factors Driving Water Consumption Change in the Yangtze River Delta under Water-Energy Correlation [J]. Ecological Economy. 2021, 37(02): 159-166. 
6. Ding et al. Change of Yangtze River Economic Belt's Industrial Structure and its Effect on Surrounding Environment from 2000 to $2015[\mathrm{~J}]$. Safety and Environmental Engineering. 2020, 27(02): 8-16.

7. Tapio P., Banister D., Luukkanen J., Vehmas J., Wilamo R. Energy and transport in comparison: Immaterialisation, dematerialisation and decarbonisation in the EU15 between 1970 and 2000 [J]. Energy Policy, 2005, 35(1): 433-451.

8. Kilimani N , Heerden J V , Bohlmann H , Roosl. Economy-wide impact of drought induced productivity losses [J]. Disaster Prevention and Management: An International Journal, 2018, 27(5), 636-648.

9. Zhang B, Wang B, Wang Z H. Role of renewable energy and non-renewable energy consumption on EKC: Evidence from Pakistan [J]. Journal of Cleaner Production, 2017, 156(7): 855-864.

10. OECD. Indicators to measure decoupling of environmental pressures from economic growth [R]. Paris: OECD,2002.

11. TAPIO P. Towards a theory of decoupling: degrees of decoupling in the EU and the case of road traffic in Finland between 1970 and 2001[J]. Transport Policy, 2005, 12(2): 137-151.

12. He X Y. Research on the decoupling relationship between China's economic growth and industrial "three wastes" emissions [D]. Harbin Engineering University, 2016. 